SHORT REPORT

\title{
Acceptability of oesophagogastroduodenoscopy without intravenous sedation: patients' versus endoscopist's perception with special reference to older patients
}

\author{
B R Thanvi, S K Munshi, N Vijayakumar, N Taub, T C N Lo
}

Postgrad Med J 2003;79:650-651

Background: Unsedated oesophagogastroduodenoscopy (OGD) is considered by most endoscopists to be a quick, safe, and well tolerated procedure. Older patients are said to tolerate it better than younger patients. However, patients' perception of the discomfort for the unsedated OGD has not been well studied.

Objective: This study was undertaken to compare (1) patients' perception of discomfort with the endoscopist's perception of patients' discomfort for the unsedated OGD, (2) tolerability between older ( $\geqslant 75$ years) and younger ( $<75$ years) patients.

See end of article for authors' affiliations

Design and subjects: A total of 130 consecutive patients attending a day case endoscopy unit were recruited for the study. The patients and endoscopist recorded their assessment using a visual analogue scale (VAS). The results were analysed using non-parametric tests. Thirty patients were excluded from the study based on exclusion criteria. Sixty three $(57 \%)$ patients were aged $\geqslant 75$ years and $37(43 \%)$ were $<75$ years.

Correspondence to:

Dr B R Thanvi, Medicine

for the Elderly, Leicester

Results: A significant difference was noted between patients' perception of the discomfort and the General Hospital,

Gwendolen Road

Leicester LE5 4PW, UK.

bthanvi@hotmail.com

Submitted

25 February 2003

Accepted 3 April 2003 endoscopist's assessment of the patient's discomfort as suggested by the overall higher VAS scores for patients (median 4.9, SD 2.6) than those of the endoscopist (median 2.2, SD 1.2), giving a significant difference in median VAS score of $3.4(\mathrm{p}<0.001)$. Older and younger patients had similar scores, with median (SD) VAS scores of 4.8 (2.5) for $\geqslant 75$ years and 4.9 (2.8) for $<75$ years. The endoscopist's median scores for these two groups were $2.2(1.2)$ and 2.1 (1.3), respectively.

Conclusions: Patients' discomfort during OGD performed without sedation was greatly underestimated by the endoscopist. There was no significant difference in acceptability between old and the young patients.

$\mathrm{O}$ esophagogastroduodenoscopy (OGD) is often carried out under topical pharyngeal anaesthesia without sedation and is generally considered a safe and well tolerated procedure. ${ }^{1}$ There are wide variations as regards the use of intravenous premedication among endoscopists. The results of a nationwide survey showed that many endoscopists in the UK used sedation. ${ }^{2}$ Premedication is not essential to endoscopy but patient tolerance is believed to improve and thus, the ease of examination. ${ }^{3}$ As unsedated gastroscopy can be unpleasant for some patients, some factors are suggested to predict poor tolerance, for example, first time endoscopy, young age, female gender, and high level of pre-test anxiety. ${ }^{4}$ This study was undertaken to compare the patient's perception of the degree of discomfort for the OGD performed under topical pharyngeal anaesthesia with that of the endoscopist's perception about patient's discomfort and also to compare the acceptability of the procedure between old ( $\geqslant 75$ years) and young patients $(<75$ years).

\section{METHODS}

One hundred and thirty consecutive patients who attended a day case endoscopy unit of a university hospital for diagnostic OGD were recruited for the study. The procedure was explained by the endoscopy nurse and then by the endoscopist. Written consent was obtained for the test. All endoscopies were performed by the same experienced endoscopist. Using a $10 \mathrm{~cm}$ visual analogue scale (VAS), all patients were asked to record their expected discomfort for the test as a pre-test score and, after completion of the test, their actual discomfort for the test as a post-test score. The endoscopist made an independent post-test assessment of his perception of patient's discomfort using a $10 \mathrm{~cm}$ VAS. Patients with cognitive impairment, previous history of endoscopy, altered sensorium secondary to sedatives or underlying illness, and those who requested intravenous sedation were excluded. Wilcoxon signed rank (non-parametric) tests were used to analyse the data for comparing patients' scores with those of the endoscopist. MannWhitney (non-parametric) tests were used to compare the scores of two age groups.

An example of a VAS used is shown in appendix 1 .

\section{RESULTS}

Out of 130 subjects, 30 were excluded from the study on the basis of the exclusion criteria: eight with a history of previous endoscopy, six with cognitive impairment, and 16 who opted for sedation. The data were analysed for the 100 subjects who were included. Their age ranged from 29-91 years. Fifty seven $(57 \%)$ were $\geqslant 75$ years of age and $43(43 \%)$ were $<75$ years of age. The mean age of the older age group was 78.4 years and that of the younger group was 52.4 years; $56 \%$ were male and $44 \%$ female.

The VAS scores of patients before endoscopy (total 610.2 and median 6.4) were significantly higher than post-test scores (total 482.9 and median 5.0) with $\mathrm{p}<0.001$. The higher VAS scores reflect a greater degree of discomfort.

Abbreviations: OGD, oesophagogastroduodenoscopy; VAS, visual analogue scale 
Table 1 Comparison of VAS scores of patients and endoscopist after the procedure

\begin{tabular}{lll}
\hline & Total VAS scores & Median (SD) scores \\
\hline $\begin{array}{l}\text { Patients } \\
(n=100)\end{array}$ & 482.9 & $5.0(2.6)$ \\
$\begin{array}{l}\text { Endoscopist } \\
(n=100)\end{array}$ & 244.7 & $2.2(1.2)$ \\
\hline
\end{tabular}

Table 2 Comparison of post-test VAS scores based on age of patients

\begin{tabular}{ll}
\hline Age (years) & Median (SD) score \\
\hline$\geqslant 75(n=57)$ & $4.8(2.8)$ \\
$<75(n=43)$ & $4.9(2.5)$ \\
\hline
\end{tabular}

The results of post-test VAS scores of patients and endoscopist are summarised in table 1.

Overall, VAS scores for patients were higher (median score 5, SD 2.6) than those of the endoscopist (median score 2.2, SD 1.2) with a median difference of 3.4 (95\% confidence interval of 2.8 to 3.9$)$. This was statistically highly significant $(\mathrm{p}<0.001)$.

The post-test VAS scores of older and younger subjects are summarised in table 2.

\section{DISCUSSION}

OGD without sedation is considered to be a safe, quick, and well tolerated procedure. ${ }^{15}$ The avoidance of sedation related morbidity and mortality is an obvious advantage and undoubtedly saves significant time and cost. Other studies, however, suggest that unsedated OGD is unpleasant, at least for some patients. ${ }^{367}$

Our patients' higher pre-test VAS scores suggest the presence of high level of expected discomfort for the procedure. Their subsequent lower post-test VAS scores reflect better tolerance of the procedure than they had anticipated. However, the significantly higher post-test VAS scores of patients compared with those of the endoscopist suggest that even an experienced endoscopist performing OGD without sedation greatly underestimates the discomfort experienced by the patients.

In contrast to previous studies suggesting better tolerance of the procedure by older subjects, ${ }^{4}$ we were unable to show any age related difference in the tolerability. This could, at least in part, be explained by the fact that earlier studies were mainly based on the endoscopist's perception alone.

Our study was not designed to compare the tolerability of OGD using only topical anaesthesia with that performed using intravenous sedation. It is technically difficult to obtain valid VAS scores on the day of the test as sedation may impair patients' ability to make an accurate assessment of their discomfort.
Gastrointestinal endoscopy is a commonly performed procedure. Patients' wishes are, therefore, of paramount importance especially in the context of informed consent and clinical governance. ${ }^{8}$ Most of the time the risks involved with the procedure are explained to the patients but the discomfort associated with it is understated. There is little doubt that in the modern patient-focused health care systems patients should be more and more involved in their care and evidence is mounting that greater involvement of patients in care produces better results. ${ }^{9}$ This is especially true for procedures that are invasive and potentially harmful or uncomfortable. In many clinical situations patients' decisions are not uncommonly in conflict with the physicians' recommendation. Nevertheless the autonomy of the patient over-rides beneficence in most circumstances and has to be respected..$^{10}$

Patients should be well informed not only about the benefits but also the risks and discomfort associated with the procedure. This will help them to make a balanced decision. Endoscopists practising OGD without sedation should recognise that they might, unintentionally, underestimate patients' discomfort.

\section{Authors' affiliations}

B R Thanvi, S K Munshi, N Vijayakumar, T C N Lo, Department of Medicine for the Elderly, Leicester General Hospital, University Hospitals of Leicester NHS Trust

N Taub, Department of Epidemiology and Public Health, University of Leicester, Leicester

\section{APPENDIX 1}

\section{VISUAL ANALOGUE SCALE (PATIENT)}

Degree of expected discomfort before procedure:

$$
\begin{array}{r}
1-2-3-4-5-6-7-8-9-10 \\
\text { (minimum) }
\end{array}
$$

\section{REFERENCES}

1 Al-Atrakchi HA. Upper gastrointestinal endoscopy without sedation: a prospective study of 2000 examinations. Gastrointest Endosc 1998;35:79-81.

2 Daneshmend TK, Bell GD, Logan RFA. Sedation for upper gastrointestinal endoscopy: results of a nationwide survey. Gut 1991;32:12-15.

3 Ross WA. Premedication for upper gastrointestinal endoscopy. Gastrointest Endosc 1989;35:120-6.

4 Campo R, Brullet E, Monteserrat A, et al. Topical pharyngeal anaesthesia improves tolerance of upper gastrointestinal endoscopy: a randomised double-blind study. Endoscopy 1995;27:659-64.

5 Chuah SY, Crowson CP, Dronfield MW. Topical anaesthesia in upper gastrointestinal endoscopy. BMJ 1991;303:695.

6 Gordon MJ, Mayes GR, Meyer GE. Topical lidocaine in preendoscopic medication. Gastroenterology 1976:71:564-9.

7 Hedenbro JL, Ekelund M, Jansson O, et al. A randomised double blind, placebo-controlled study to evaluate topical anaesthesia of the pharynx in upper gastrointestinal endoscopy. Endoscopy 1992;24:585-7.

8 Scally G, Donaldson $\amalg$. Clinical governance and the drive for quality improvement in the new NHS in England. BMJ 1998;317:61-5.

9 Kaplan SH, Greenfield S, Ware JE Jr. Assessing the effects of physicianpatient interactions on the outcomes of care. Med Care 1989;27(suppl 3):S1 10-27.

10 Balint J, Shelton W. Regaining the initiative. Forging a new model of the patient-physician relationship. JAMA 1996;275:887-91. 